\title{
Práticas Avaliativas Consideradas Positivas por Alunos do Ensino Superior: aspectos didático-pedagógicos
}

\author{
NEUSI APARECIDA NAVAS BERBEL \\ Professora do Departamento de Educação - Centro de Educação, Comunicação e \\ Artes - CECA da Universidade Estadual de Londrina - UEL \\ berbel@uel.br \\ CLÁUDIA CHUEIRE DE OLIVEIRA \\ Professora do Departamento de Educação - Centro de Educação, Comunicação e \\ Artes - CECA - da Universidade Estadual de Londrina - UEL \\ cchueire@uel.br \\ MAURA MARIA MORITA VASCONCELLOS \\ Professora do Departamento de Educação - Centro de Educação, Comunicação e \\ Artes - CECA - da Universidade Estadual de Londrina - UEL \\ morita@sercomtel.com.br
}

\begin{abstract}
Resumo
Este artigo relata parte de uma investigação acerca da avaliação da aprendizagem em licenciaturas, por meio da Metodologia da Problematização. O foco da problematização foram as práticas avaliativas positivas de 48 docentes indicados por alunos em pesquisa anterior. Buscou-se saber que fatores explicam tais práticas avaliativas e que lições podem ser delas extraídas, referentes aos aspectos didático-pedagógicos. Nas entrevistas, dois grupos de aspectos foram verificados: os que revelam os sinais de mudança da prática avaliativa e as modalidades de avaliação praticadas, em suas combinações e características. As lições extraídas da análise, com apoio na literatura, valorizam: práticas que privilegiam a orientação e o acompanhamento dos alunos visando ao aprendizado destes; a indissociabilidade entre a avaliação e a metodologia de ensino, e a prática de avaliação vinculada a um alto nível de exigência. Evidenciou-se também que um movimento de continuidade/ruptura nos processos de avaliação os aproximam da avaliação formativa.

Palavras-chave: avaliação da aprendizagem, práticas avaliativas positivas, ensino superior, metodologia da problematização.
\end{abstract}

\section{Resumen}

Este artículo relata parte de una investigación sobre la evaluación del aprendizaje en licenciaturas, a través de la Metodología de la Problematización. El foco de la problematización se constituyó partiendo de las prácticas de evaluación positivas de 48 docentes indicados por alumnos en investigación hecha anteriormente. Se buscó saber qué factores explican tales prácticas de evaluación y qué lecciones pueden ser entresacadas de ellas, sobre los aspectos didáctico-pedagógicos. En las entrevistas, se observaron dos grupos 
de aspectos: los que desvelan las señales de cambio de la práctica de evaluación y las modalidades de evaluación practicadas, en sus combinaciones y características. Las lecciones entresacadas del análisis, apoyadas en la literatura, valoran: prácticas que valoran la orientación y el acompañamiento de los alumnos visando su aprendizaje; la indisociabilidad entre la evaluación y la metodología de enseñanza, y la práctica de evaluación vinculada a un alto nivel de exigencia. Además, se observó también que un movimiento de continuidad/ruptura en los procesos de evaluación los acerca de la evaluación formativa.

Palabras-clave: evaluación del aprendizaje, prácticas de evaluación positivas, enseñanza superior, metodología de la problematización.

\begin{abstract}
This study reports on part of an investigation concerning learning evaluation in Teaching Accreditation Courses, by means of a Problematization Methodology. The problematization focused on positive evaluation practices of 48 teachers as pointed out by students in a previous research. Explanatory factors for such evaluation practices and possible didacticpedagogical lessons elicited from them were researched. In the interviews, two groups of aspects were identified: those revealing signs of change in evaluation practices and the types of evaluation practices adopted, including their combinations and features. The lessons derived from the analyses, based on available literature, value practices which focus on supervision and accompaniment of students aiming at fostering their learning; the inextricable link between evaluation and teaching methodology, and evaluation practice allied to a high level of demand. It was also found that continuity and rupture movements in evaluation bring them close to formative evaluation.

Key words: learning evaluation, positive evaluation practices, higher education, problematization methodology.
\end{abstract}


Observar, compreender, explicar uma situação não é avaliá-la; essas ações são apenas parte do processo.

Para além da investigação e da interpretação da situação, a avaliação envolve necessariamente uma ação que promova a sua melhoria.

Jussara Hoffmann

As idéias relativas a uma avaliação mais formativa, reveladora de uma atitude construtiva e comprometida com o aprendizado do aluno têm, pouco a pouco, conquistado espaços nos ambientes educativos. No caso do ensino superior, as práticas avaliativas realizadas por alguns professores de licenciatura, indicados por alunos de graduação, expressam essas possibilidades (Berbel et al., 2001; Vasconcellos, 2002). Porém, sabemos que para caminhar no sentido de uma educação emancipadora, é necessária uma lógica universitária que questione, desvele e critique o conhecimento, atribuindo-lhe significado. Tal idéia nos remete à grande responsabilidade da universidade, pois é ela a formadora de profissionais que irão atuar nas escolas e que poderão transformar as práticas avaliativas atuais.

Nas licenciaturas, essa questão da avaliação torna-se ainda mais delicada: esses cursos formam professores e, assim, devem preparar de forma mais aprofundada os futuros profissionais no que se refere à avaliação da aprendizagem, bem como possibilitar a eles a vivência de práticas diferenciadas e inovadoras de avaliação.

Como professoras de Didática, temos vivenciado a problemática da avaliação da aprendizagem diretamente relacionada com a nossa prática docente, que é a da formação profissional para o ensino. Entendemos que, hoje, atuar na formação de professores também implica investigar práticas avaliativas marcantes e positivas vivenciadas durante o processo de formação, pois com isso pode-se enriquecer e solidificar a construção de espaços de reflexão e ação para a prática pedagógica que se pretende estruturar. Buscamos, desse modo, conhecer mais de perto as práticas avaliativas que possivelmente romperiam com padrões tradicionais de atuação docente e, com isso, promoveriam melhores condições de aprendizagem para os alunos, de elaboração do conhecimento e conseqüente desenvolvimento.

Tivemos algumas preocupações que nos mobilizaram para o estudo, entre elas o fato de os professores que atuam nas licenciaturas em geral terem tido formação em licenciatura, e isso os habilitou para serem professores e formar novos professores. Sendo esse o caminho, como explicar a atuação positiva de alguns, enquanto outros têm atuação negativa, como revelaram os alunos de diferentes licenciaturas, em 
pesquisa anterior? Se alguns professores atuam positivamente com seus alunos em relação à avaliação, o que seria necessário para que outros docentes também o fizessem? Sabemos que pode ser o resultado de um conjunto de fatores, por isso nossa intenção, com a investigação, foi revelar a professores e alunos das licenciaturas e outros, nossas análises. Buscamos, com a divulgação da pesquisa, oferecer uma possível referência para a reflexão sobre o assunto, a partir da construção que realizamos, na associação entre o teórico e o empírico.

Em pesquisa anterior acerca da avaliação da aprendizagem, portanto, consultamos os alunos das 14 licenciaturas da instituição em que atuamos, na época em número de 738 , dos quais obtivemos a colaboração de 428. Surpreendemo-nos com suas respostas, que classificamos em cinco importantes dimensões da avaliação: pedagógica, instrumental, emocional, ritual-corporal e ética. Analisamos seus aspectos positivos e negativos, assim como suas consequiências para a formação do futuro professor, e os resultados encontram-se publicados em Berbel et al. (2001).

Reconhecendo a necessidade de continuidade da investigação, visando a contribuir em algum grau para a construção da teoria sobre a prática concreta, decidimos, em novo projeto de pesquisa, ouvir os professores das mesmas licenciaturas.

O caminho metodológico para a investigação seguiu as cinco etapas da Metodologia da Problematização com o Arco de Maguerez, conforme Bordenave e Pereira (1982) e Berbel (1995, 1998 e 2004). Trata-se de um caminho que parte da realidade para aprender com ela e para com ela contribuir, por meio de algum grau de intervenção sobre a parcela investigada, como conseqüência do estudo realizado.

Como observação da realidade, tomamos todo o corpo de informações da pesquisa anterior, que serviu de base para a elaboração do problema da nova investigação. Por meio dessa investigação buscou-se saber que fatores explicam as práticas avaliativas dos professores indicados pelos alunos e que lições podemos extrair dessas experiências para o conjunto dos professores das licenciaturas.

$\mathrm{Na}$ etapa da teorização, combinamos informações da literatura com as informações colhidas entre os professores. Buscamos, assim, fundamentar respostas para os três pontos-chave definidos para o estudo: o que move a prática avaliativa; a construção da prática avaliativa; os aspectos didático-pedagógicos das práticas de avaliação no ensino superior, mais especificamente nas licenciaturas.

Tomando os cuidados técnicos e éticos para colher informações, entrevistamos 48 professores, eleitos pelos alunos na pesquisa anterior como aqueles que apresentavam práticas avaliativas consideradas por eles 
como positivas, e que concordaram em colaborar conosco. Utilizamos um roteiro semi-estruturado, buscando saber dos professores aspectos como: a sua formação inicial e continuada, o tempo e tipo de atuação na docência, a descrição mais ampliada da experiência destacada pelos alunos, a avaliação que faziam de sua própria experiência avaliativa, além de influências que tiveram sobre sua prática atual. Parte dessa informações já foram exploradas em outros artigos.

Neste artigo, focalizamos uma síntese dos resultados da investigação referente ao terceiro ponto-chave, que tratou dos aspectos didático-pedagógicos das práticas positivas de avaliação. Para isso, salientamos dois grandes grupos de aspectos que serão valorizados, tendo em vista captar o sentido atribuído a eles pelos docentes, assim como estabelecer as ligações entre as informações. Tomamos como pressuposto que estudar a avaliação é entrar na análise de toda a pedagogia que se pratica, como afirma Gimeno Sacristán (1998, p. 265).

Um primeiro grupo reúne vários sinais de mudança da prática avaliativa que se conhece no Ensino Superior. Esses sinais de mudança revelam um evidente esforço dos professores em acrescentar algo a seus alunos, na busca de ampliar a sua formação. Tais sinais são encontrados nas manifestações da intencionalidade das práticas avaliativas desses professores, tendo em vista o futuro profissional de seus alunos; nos critérios estabelecidos para os alunos nas avaliações; assim como na conjugação da teoria com a prática em suas áreas.

O segundo grupo de aspectos focaliza as modalidades de avaliação e seus desdobramentos. São várias formas de combinar procedimentos e instrumentos de avaliação, entre as quais salientamos algumas menos usuais. Outras práticas se aproximam da avaliação formativa, e entre elas merece destaque a supervisão e o acompanhamento do aprendizado dos alunos, o diálogo, o feedback, as chances que são dadas para o aluno alcançar os objetivos, e, também, a consideração menor da nota, apresentada como uma conseqüência do processo. A seguir apresentamos uma síntese do que analisamos.

\section{OS SINAIS DE MUDANÇA}

As práticas avaliativas positivas dos professores revelam rupturas com o paradigma tradicional da educação, em graus diferenciados, diante de uma tradição secular, fortalecida oficialmente ao longo do tempo. Isso representa a esperança de inovação na educação, pelo movimento de atualização das suas ações pedagógicas, rompendo com as amarras e construindo a sua história. 
Vasconcellos (2003) realça a importância da intencionalidade do professor como fator essencial à mudança das práticas avaliativas, com o sentido de transformação, pois a mudança na intencionalidade da avaliação, mesmo sem maiores mudanças em outros aspectos num primeiro momento, tem possibilitado avanços significativos do trabalho (p. 43). Sem retirar o valor das outras dimensões, o autor enfatiza que a questão da intencionalidade é o problema nuclear da avaliação. Gimeno Sacristán (1999) partilha desse ponto de vista, ao afirmar que compreender esse elemento dinâmico e motor é fundamental para qualquer educador, especialmente em um contexto de valores imprecisos e de rotinas estabelecidas diante de desafios importantes que exigem respostas comprometidas (p. 33).

$\mathrm{O}$ autor ainda declara:

O papel da intenção na ação é decisivo a tal ponto que, para entender qualquer delas, mais que indagar pelas causas, o que necessitamos é interpretar a intenção ou propósito do agente. Ao nos movermos neste ponto, logo ficam excluídas as ações mecânicas e involuntárias as quais, para o nosso propósito, não têm a categoria de serem plenamente humanas. (1999, p. 33)

A intencionalidade é, portanto, condição necessária para a ação. Voltamos o nosso olhar para a revelação da intenção, do propósito com que os professores avaliam seus alunos, e a isso poderíamos adicionar a questão dos objetivos ou finalidades. A esse respeito, podem ser formuladas duas questões: para que direção estão voltadas as práticas avaliativas relatadas? Que resultados os professores desejam alcançar e verificar?

Expressando-se de várias maneiras, nossos entrevistados dizem que se empenham em formar o profissional e estão comprometidos com isso. Há os que têm a intenção de formar o profissional ou preparar para a profissão: eu encaro que não estou aqui só para dar aulas, mas para formar um profissional (H3). Eu justifico porque eu faço isso com eles [...] tem que ser profissional. [...] Então eu gostaria que eles saíssem da graduação já um pouco articulados (M2). E há os que focalizam a profissão do professor ou do educador: para que eles possam ensinar com mais qualidade, que eles possam ter mais argumentos práticos e verbais[...] a gente se preocupa em passar noções básicas do nosso conteúdo para que eles possam ter mais artifícios de ensino (K2).

Mesmo tendo propósito semelhante, cada professor encontra uma forma específica de contribuir, inventa uma forma sua de dirigir o seu processo de formação do profissional, de realizar a sua intencionalidade. Com seu trabalho, A1 busca criar a possibilidade de formar bons educadores [...] para atuarem na formação do cidadão lá fora [...]. Tento buscar a liberdade de formar cidadãos. E a gente forma o cidadão já dentro da escola. 
Para J2, antes do profissional está o homem: a minha avaliação está no homem, a minha preocupação está em formar o homem, não só o profissional, porque antes de tudo ele deve ser homem, cidadão. E A3 mostra a sua posição: $a$ questão do compromisso político, eu acho que é o que dá o diferencial na questão da prática da sala de aula, tanto do ponto de vista do professor como do aluno.

Pelos exemplos citados, podemos deduzir que a intencionalidade do professor vai impregnando seu trabalho com os alunos de modo que estes também passem a aprender imbuídos dessa intencionalidade, que alguns vão caracterizando como uma práxis, reveladora da construção humana.

Outros professores enfatizaram a busca do desenvolvimento de habilidades complexas do pensamento, como a reflexão, a crítica e a consciência crítica, a resolução de problemas, a clareza sobre processos e a organização de idéias. Para L1: a prova não é para penalizar o aluno ou para pegar o mau aluno, a prova é um instrumento de reflexão, de aprendizagem. O professor F4 nos explicou que os alunos não podem só ficar recebendo informações sem colocar em prática o seu pensamento, o exercício do pensamento, de uma idéia, de uma opinião, de uma crítica. E A1 explicitou: estou muito mais preocupado com a consciência crítica do aluno do que com os conceitos.

Formar o leitor e o pesquisador, e incentivar a elaboração de trabalhos para serem publicados, também são exemplos de atividades complexas, próprias da vida acadêmica no ensino superior. Essas atividades, além de prepará-los para a profissão, ainda os incentivam para a continuidade da carreira. Para H1: o aluno tem que ter o domínio da línguapátria e eu não estou preparando o aluno só para dar aulas, mas para ter um perfil também, de pesquisador, de leitor. Por sua vez, afirmou H3: na minha avaliação, o que eu cobro deles é basicamente a elaboração de trabalhos para serem publicados.

A preocupação com o desenvolvimento da autonomia e a conquista da independência pelos alunos também aparecem nas respostas dos professores. Por exemplo, na fala de A2, que enfatiza a necessidade de levar os alunos a resolver problemas, porque é para isso que estamos aqui. A gente precisaria trabalhar mais para desenvolver [...] essa condição de independência. E na fala de $\mathrm{H} 1$, ao explicar que o papel do professor também é esse, de estar incomodando o aluno com certas questões para ver se ele começa a refletir, ou a procurar respostas. [...] A avaliação é mais para [...] que ele consiga construir essa consciência, uma autonomia afetiva, intelectual e moral.

Os professores mostram reconhecer a importância de levar os alunos a ultrapassarem a posse do conhecimento, passando pelo processo de reflexão e de outras habilidades intelectuais para lidar com os conhecimentos. Ao estabelecer objetivos ou metas cujas realizações sejam de nível complexo, o professor vai fazendo com que, gradativamente, seus alunos se tornem cada vez mais responsáveis e protagonistas de suas 
aprendizagens, pelas habilidades que vão desenvolvendo. Essa intencionalidade é bastante apropriada para o nível de formação no ensino superior. Tais práticas, portanto, estão impregnadas de valor pedagógico. Afinal de contas, a educação e, conseqüentemente, a avaliação é "uma invenção dirigida, uma construção humana que tem sentido e que leva consigo uma seleção de possibilidades, de conteúdos e de caminhos", como nos lembra Gimeno Sacristán (1999, p. 33).

Nesse sentido, é preciso que os objetivos e metas de níveis de complexidade e relevância acadêmica sejam percebidos como algo que realmente tenha sentido e seja desejado pelos professores, de modo que, ao lhe atribuírem um significado pessoal, caracterizem também uma das facetas de seu profissionalismo docente.

O professor revela sua intencionalidade também ao propor, discutir ou definir os critérios de avaliação da aprendizagem para seus alunos e com eles. Em geral, a declaração de critérios tem servido para estabelecer com clareza a conduta de professores e alunos em face da atribuição de valor ao objeto da avaliação, antes que ela ocorra, dando significado à mesma. Ao definir os critérios para a avaliação, o professor realça o que é mais importante, ou, segundo Luckesi (1996), o que é "relevante" para ser avaliado. Ao declarar os critérios, e mesmo ao estabelecê-los com os alunos, o processo avaliativo se torna mais aberto, democrático e orientado.

Considerando-se que a definição dos critérios tem relação com a intencionalidade presente na avaliação e que esta é reveladora dos valores e crenças que movem o professor, imaginamos a existência da variedade e até mesmo da arbitrariedade de que podem se revestir. Turra (2003, p. 6768) chama à atenção para alguns aspectos relacionados aos critérios. Afirma que tanto mais adequados eles serão quanto mais representativos forem das decisões do coletivo dos professores; que serão mais úteis quanto maior for a percepção e a aceitação do coletivo de alunos implicados no processo de avaliação. Além disso, que serão mais efetivos quanto mais resultarem de acordo ou combinação entre o coletivo dos professores e o coletivo dos alunos.

Segundo a mesma autora, é imprescindível que os critérios de avaliação sejam a expressão da qualidade das aprendizagens resultantes da proposta didático-pedagógica [...], representativos do que é essencial na área de conhecimento. Os critérios podem, nesse sentido, auxiliar o avaliador na observação, no questionamento, na reflexão teórica, e na crítica das produções resultantes da relação sujeito - objeto de conhecimento - experiências vividas na prática social (p. 69).

Por outro lado,

Em situações de avaliação, voltadas para a verificação do rendimento escolar, os critérios [...] cumprem o papel de auxiliar o avaliador na classificação do 
aproveitamento escolar, em relação às aprendizagens desenvolvidas, podendo estar associados à nota. (Turra, 2003, p.69)

O segundo papel - associado à nota - é o mais usual, mas o primeiro, sem dúvida, é o que carrega maior intencionalidade consciente do ponto de vista didático-pedagógico.

Vários professores explicitam o uso dos critérios em suas avaliações. Entre eles, há os que os definem e os apresentam aos alunos; os que esclarecem até mesmo o conceito de critério; os que usam o critério para declarar o nível de exigência e também atribuir a nota; os que o tomam como sinônimo de objetividade; e os que revelam os aspectos que consideram ser seus critérios.

Por exemplo, B3 explica que os alunos apresentam seus trabalhos em painel e ele estabelece os critérios de avaliação: passo com eles com antecedência o que são critérios. Explica ainda que geralmente, no primeiro painel eles aprendem qual é o critério de avaliação e no segundo eles corrigem as falhas. Sem mencionar a palavra critério, $\mathrm{H} 1$ define os pontos elementares que um bom professor deve ter para trabalhar em sala de aula. Explica que para os alunos serem aprovados, eles têm de demonstrar determinadas competências que ele avalia como sendo as mais interessantes para um bom professor.

Um exemplo de forma de avaliar considerada por K2 como a mais pertinente, por meio da qual considerou que teria mais controle, foi a filmagem [das práticas dos alunos], pela qual poderia parar e analisar as ações com critério, estabelecendo nota para cada tipo de ação que eles realizam. Procurando trilhar novos caminhos para tentar fazer uma avaliação mais coerente, mais justa, que beneficie mais o aluno, sendo encarada como feedback e não como punição, M1 toma esses valores como critérios e alerta para o fato de que os alunos sabem que estão sendo observados, avaliados nesses critérios.

Outro exemplo interessante é o de F1, que, ao mesmo tempo que informa aos alunos como serão avaliados, dá abertura para a participação dos mesmos nessa decisão. F1 coloca para os alunos: se você quer fazer algo que é diferente disso que eu estou propondo, você coloque no seu texto, que se tiver coerência eu não tenho porque não aceitar.

Juntamente com as iniciativas de explicitação de critérios para as avaliações, encontramos uma manifestação de definição dos critérios a posteriori, por K2, que nos contou: seleciono, por exemplo, dez ações. Nem sei quais vão ser. No vídeo, do momento tal até o momento tal, eu seleciono dez ações e dessas ações eu dou uma pontuação em cima delas. Caso os alunos solicitem uma revisão de prova, K2 explica: passo o filme e falo: aqui aconteceu isso e isso, e por isso você teve a nota tal.

Um outro professor manifestou a sua dificuldade de avaliar as pessoas que estão acima da média e de transformar o resultado em nota: às 
vezes eu penso: o cara tirou nove. Será que ele não podia ter tirado dez? Então eu deixo de lado para pensar, depois eu vejo (K1).

Sabemos que cada professor constrói o seu próprio sistema de avaliação e, como afirma Gimeno Sacristán (1998), utiliza seus próprios padrões de valores, sua idéia de rendimento ideal, suas crenças sobre o que é que denota cada resultado ou dado observado etc. São vários os fatores que compõem os esquemas mediadores do avaliador. Enquanto para um o importante é a capacidade de argumentação do aluno, para outro é o ajuste da resposta esperada; quando um valoriza a expressão ortográfica correta, outro se fixa mais na fluência da linguagem (p. 308).

No entanto, principalmente pela observação dos dois últimos exemplos, reforçamos a importância do estabelecimento claro dos objetivos a alcançar com o ensino, a partir dos quais os critérios de avaliação poderão ser definidos. Cabe focalizar o que é relevante para ser avaliado e reconhecer o valor orientador dos critérios, tanto para os alunos quanto para os próprios professores.

Encontramos ainda nas falas dos professores uma preocupação de relacionar teoria e prática nas atividades de ensino e aprendizagem. Também é revelador o aspecto de intencionalidade que envolve a avaliação. Pensar nessa aproximação entre a teoria e a prática nos remete, por oposição, à idéia da fragmentação do trabalho pedagógico, cuja superação só poderá ocorrer, conforme Kuenzer (2004), por meio da destruição das condições que produzem tal fragmentação no contexto maior da sociedade e não somente na escola.

Os professores, pela aquisição de novos saberes, podem passar a entender a possibilidade que a educação oferece para superar essa limitação por meio de alternativas de condução do processo de formação. Dessa forma, pode-se encontrar, primeiramente no discurso e gradativamente nas suas ações, o gérmen revolucionário da práxis.

Kuenzer (2004) lembra que Marx e Engels formularam a concepção do objeto como produto da atividade humana, entendida não abstratamente, mas como atividade real, objetiva e material. A questão do conhecimento, em Marx, vai estabelecer uma clara relação entre o trabalho intelectual, teórico, e a dimensão empírica da realidade, que se deixa perceber, a partir dos quais os significados vão sendo construídos. É pelo movimento da práxis, pela interação com a natureza, com o mundo, que o homem conhece e pode agir para transformar esse mundo.

Em Marx, estão os fundamentos para compreendermos os componentes da teoria (reflexão) e da prática (os fazeres) que se integram na práxis. Vázquez (1977, p.197-198) discute e esclarece essa relação e afirma que a práxis produtiva é: 
a práxis fundamental porque nela o homem não só produz um mundo humano ou humanizado, no sentido de um mundo de objetos que não só satisfazem necessidades humanas e que só podem ser produzidos na medida em que se plasmam neles finalidades ou projetos humanos, como também no sentido de que na práxis produtiva o homem se produz, forma ou transforma a si mesmo.

É possível que os professores, ao valorizarem a integração entre a teoria e a prática nas atividades com seus alunos, estejam imbuídos de finalidades humanas de transformação dos mesmos, para que possam humanizar o meio, por suas ações específicas.

Ao explicar, por exemplo, sua forma de avaliar, K1 salienta: com esta avaliação, a gente tem tentado um equilíbrio entre a parte teórica e a parte prática.

Os alunos de B1 são levados a realizar um trabalho que lhe permite afirmar: fugindo dessa avaliação de fazer prova para ver domínio teórico, o aluno fica muito mais motivado. [...] você vê um envolvimento maior, mais motivação, principalmente pela vinculação com a prática. E B1 fica satisfeito por ver a preocupação do aluno com o trabalho porque ele começa a perceber que isso reflete no campo profissional.

O Professor M1 nos explica a sua posição: quando eles falam da relação teoria/prática [...] acho que elas têm que correr simultaneamente, uma coisa alimentando a outra, uma vai refletir as falhas que possivelmente possa ter havido na outra; existe uma relação direta, não pode separar. É por isso que M1 gosta da metodologia da problematização, [...] justamente por essa vivência que você tem de a cada etapa do Arco você estar podendo realimentar o processo, fazer uma avaliação direta, avaliação processual.

De forma simples e direta, G1 afirma que no caso das avaliações, sempre coloco uma problemática que o aluno vai ter que responder, sempre relacionando a teoria e a prática. Como último exemplo, trazemos a fala de L5, assumindo a avaliação como um processo:

Esta aproximação (teoria e prática) é que me dá possibilidade de olhar a avaliação de maneira mais amadurecida, esta que é um processo que me coloca para ser avaliada pelos meus alunos e coloca os alunos para que eu possa avaliá-los. A vinculação da teoria com a prática fez com que nós, em sala de aula, assumíssemos a avaliação como um processo. (L5)

A ruptura com o paradigma tradicional do ensino delineia-se na universidade, nos cursos de Licenciatura, mesmo em graus diferenciados. Isso será cada vez mais possível, pelo entendimento de que uma teoria é prática, na medida em que se materializa por meio de uma série de mediações. A teoria em si não transforma o mundo, mas pode contribuir para a sua transformação, se assimilada pelos que vão ocasionar, com seus 
atos efetivos, tal transformação, como podemos aprender com Vázquez (1977).

Percebemos, por meio dos "sinais de mudança" aqui demonstrados, que aos poucos, pelas atividades realizadas, a avaliação em si e o trabalho pedagógico docente como um todo vão se alinhando aos mesmos propósitos formadores.

\section{AS MODALIDADES DE AVALIAÇÃO E SEUS DESDOBRAMENTOS}

Como avaliam os professores entrevistados? Segundo Hoffmann (2001), defensora de uma avaliação mediadora da aprendizagem dos alunos, a sala de aula é um cenário organizado para que o aluno aprenda em múltiplas dimensões; processo avaliativo que se propõe mediador, implica uma organização do ensino que torne os alunos produtores de conhecimento. Ou seja, implica a organização de experiências educativas significativas de toda a natureza, que tenham por objetivo sua atividade intelectual. Afirma a autora que:

Otimizar espaços significativos de aprendizagem consiste em ampliar, para alunos $e$ professores, oportunidades de interação com objetos de conhecimento, diversificando as atividades, os portadores de textos referentes [...], e desenvolvendo-as [...] de forma gradativa e complementar. [...] Os estudantes constroem saberes e valores a partir de um conjunto de experiências vividas. ( $\mathrm{p}$. 147)

Assim, quanto mais amplas forem as oportunidades de provocar e acompanhar o aluno em sua interação com o objeto de estudo, e agir sobre ele ou a partir de agentes culturais mediadores, maior será o conhecimento das formas de aprendizagem desenvolvidas e dos conceitos de que ele se apropria. Vejamos como os professores entrevistados conduzem a avaliação considerada pelos alunos como positiva.

Uma das características que marcam as avaliações positivas é a combinação de várias formas de avaliar, e isso mostra a disposição dos professores de ultrapassar o velho padrão do registro de duas notas semestrais nas disciplinas, como conseqüência de duas aferições da aprendizagem. São várias formas que representam o conjunto de atividades desenvolvidas pelos alunos como proposta da disciplina ou a culminância de conjuntos de atividades de aprendizagem, como passamos a exemplificar.

O professor H1 avalia por meio do estágio e do relatório do estágio, utiliza-se de avaliações escritas, de avaliações orais, de avaliação do 
processo e do professor pelos alunos. Se percebe que a classe baixou o ritmo, as expectativas, os olhares, ele dá uma parada e faz uma avaliação que chama de correção de rota (bimestralmente). Ainda, segundo H1, faz uma avaliação de docente com critérios, quase os mesmos que eles usaram pra avaliar a prática docente no estágio, ou mesmo [os] que nós utilizamos para avaliar a prática docente deles.

O professor B1 utiliza a estratégia de relatório em face de uma situação do cotidiano, a respeito da qual o aluno faz uma análise e busca elementos na teoria. Utiliza também casos que já atendeu, para que seja feita uma análise em grupo, pelos alunos. Gosta de avaliar com trabalhos feitos por pequenos grupos, em que a participação também entra como uma das notas.

Muitos professores nos indicaram que fazem uma combinação de várias formas de avaliar, como é o caso de B2 que utiliza relato da própria aula pelos alunos; provas em grupo, com consulta, como se fossem trabalhos feitos em casa; estudo de temas a respeito dos quais os alunos fazem uma peça de teatro, entre outras atividades.

É o caso também de F2 que, com os alunos de $4^{\circ}$ ano, faz uma composição com trabalhos para os quais apresenta o tema e os alunos têm que buscar os textos que vão analisar. Esse professor também emprega prova oral e prova escrita, em que normalmente prepara três ou quatro questões, ou então uma questão com um único enunciado, mas com uma variedade de textos [...] para que eles possam escolher aquele texto com o qual eles tenham maior afinidade. Em outro instrumento de avaliação, o professor passa o enunciado com uma semana de antecedência e os alunos refletem acerca da proposição dada, e na semana seguinte chegam e escrevem o texto na sala. O professor F2 explica que em suas avaliações esta questão da escolha é uma coisa regular, pois ele nunca os obriga a fazer aquela questão, necessariamente. Eu gosto de pensar em alternativas variadas, alternativas que garantam a eles também alguma liberdade, porque, por mais que eu goste de montar provas elaboradas, eu gosto que eles pensem para responder, nos disse F2. O seu grande objetivo é despertar, neles, a reflexão, e não prejudicá-los.

Conforme revelou L5, suas provas são sempre com consulta, mas deixa claro para os alunos que isso não significa cópia. Trabalha também com pequenos seminários, pequenos debates, trabalhos em grupo seguidos da produção de pequeno relatório. L5 sempre tem um conjunto de trabalhos e uma prova individual: somo tudo e volto os resultados para eles.

F3, por sua vez, faz uma série de avaliações; seus alunos participam de seminários e de aulas dialogadas. O professor entrega os textos, e os alunos (em grupo de três) preparam com ele a aula, isso como uma das avaliações. Outra avaliação é o seminário propriamente dito. Além disso, solicita 
resenhas de artigos, de textos, em que os alunos fazem uma avaliação reflexiva, respondendo algumas questões. F3 corrige e devolve para eles. Tudo isso faz parte da avaliação de processo. Tem ainda a auto-avaliação em que eles se avaliam, avaliam também o professor ao final do ano. Completou F3: a tentativa é de uma avaliação mais justa. É algo mais reflexivo.

Fazer a avaliação de várias formas e em várias situações, segundo Vasconcellos (2003), é uma forma de superar a concentração em determinados momentos especiais. A finalidade desse tipo de prática, porém, não deve ser arrumar mais formas de "gerar nota" para o aluno, e sim acompanhar efetivamente o processo de conhecimento (p. 104) e, completaríamos, tomar as providências necessárias diante dos resultados, para garantir o alcance dos objetivos, pelos alunos.

Dentre os diversos procedimentos de avaliação, revelados pelos entrevistados, alguns se apresentam como formas especiais de avaliação, por seus formatos pouco usuais, incluindo uma certa dose de inovação nas práticas avaliativas que, entre outras explicações, podem se dar como conseqüência de suas experiências bem sucedidas, vividas enquanto alunos, ou a partir da sua liberdade de gerar alternativas, garantida pela autonomia didático-pedagógica no ensino superior. Exemplificamos com alguns relatos.

Começamos com $\mathrm{H} 2$ que realiza muitas atividades nas quais existe o conceito de participação, pois não é pela nota. H2 não faz provas com questões. Faz uma outra avaliação do conteúdo, das discussões teóricas, e explica: termina sendo natural, a partir do momento em que eles vão ter que dar o retorno daquilo pra comunidade. Um segundo exemplo é o de A2, que entra na sala, e, dependendo do tempo, dá uma hora de aula, explica algumas coisas para os alunos e fala: agora vamos resolver um problema aplicando esse negócio. O professor explica que não se pode ficar muito só no blá, blá, blá. Compensa, às vezes, cortar um pouco do conteúdo, dar as coisas mais resumidas, mais condensadas, mas que eles entendam. Para A2 é uma avaliação simples. Ele normalmente não foge do conteúdo dado, e frisa muito bem o que acha que é importante daquilo que foi dado.

$\mathrm{O}$ professor H3 avalia, basicamente, pela elaboração de trabalhos para serem publicados. Disse-nos: essa é a forma que eu acho que eu estou incentivando eles e ao mesmo tempo estou trazendo algo interessante: o aluno gera $o$ dado e vê o produto final. Os professores $\mathrm{K} 1 \mathrm{e} \mathrm{K} 3$ utilizam a filmagem para a avaliação de comportamentos que consideram de domínio necessário, lançando mão de uma lista de checagem. Os professores conjugam a sua avaliação com a dos alunos e a auto-avaliação de quem foi filmado. K3 utiliza também a análise e solução de casos, pelos alunos, para avaliá-los.

Entre vários tipos de trabalhos e provas feitas em casa, para cujas respostas os alunos precisam ler e criar situações, mostrando os princípios 148 
e conceitos envolvidos, B2 lança mão de um instrumento de avaliação contínua que chama de "só entre nós". Para saber coisas do tipo: se o aluno estava tomando alguma medicação; se tomava, qual era o problema; se tinha algum tipo de condição que pudesse interferir nos itens da aula etc.

Temos também a combinação de seminário com um relatório de seminário, elaborado nos moldes de uma revista científica, como orienta M2. Segundo o professor: não é um relatório como muitos professores fazem, tem que ter um certo rigor científico. Além disso, M2 também utiliza uma prova em dupla feita em casa, de questões bem amplas que podem ser respondidas em 24 horas.

Um último exemplo especial é o do diário de classe, utilizado por $\mathrm{C} 1$. Para este professor, é um instrumento muito rico, pois você percebe perfeitamente a questão da aprendizagem do aluno e quanto ele se solta para colocar o que ele pensa sobre os assuntos. C1 afirma que, quando se analisam os diários mais no final do ano, o aluno já está refletindo, assumindo posições e referências, e isso é bastante interessante.

O registro de muitos exemplos se dá pela variedade de situações, que podem vir a ser inspiradoras de nossos possíveis leitores. Observamos que, embora pouco usuais, a maioria delas mantém alguma forma de atividade escrita. Vasconcellos (2003) chama a atenção para o fato de que, às vezes, na busca de mudança das formas, o professor vai abolir a avaliação escrita por ser considerada uma forma tradicional. $O$ autor salienta que a avaliação escrita é importante para que o professor tenha melhores condições de acompanhar a evolução da aprendizagem de seus alunos e pela importância também de garantir o domínio da escrita pelo aluno, que sabemos ser tão elementar e tão problemática, até mesmo no ensino superior.

O importante é que essas alternativas "inovadoras" e as formas de administrá-las (utilizadas nas licenciaturas) possam garantir o alcance dos objetivos necessários para o desempenho do futuro profissional docente e também para a sua vida em sociedade. Deve-se considerar o desenvolvimento de habilidades intelectuais e de posturas mais amplas; não apenas uma mudança superficial do formato.

Encontramos nas respostas de nossos entrevistados muitos relatos de experiências de avaliação com características que as aproximam da avaliação formativa.

A supervisão ou o acompanhamento do aluno é uma atividade típica da modalidade de avaliação formativa. Constitui a grande oportunidade de aproximação entre professor e aluno, para conhecer de perto seu desempenho e, conseqüentemente, seu êxito e/ou suas dificuldades. Recortamos das falas dos professores algumas passagens para ilustração: pra fazer um relatório, pra fazer uma análise em casa e em grupo, eles 
têm supervisão. Tem todo um acompanhamento com supervisão semanal (B1). A gente marcava encontro no meu horário de permanência, para estar dando a supervisão, se era por ali mesmo, se não era (B2). Depois no tempo da supervisão a gente tinha um espaço pra discutir e eu procurava sempre reforçar tudo que eles tinham feito de positivo, de certo, de melhor no trabalho (B5). Com conhecimento de causa, C4 afirma:

O aluno, quando tem essas avaliações freqüentes, fica sabendo se está aproveitando, se está progredindo e, em tempo, está corrigindo. [...] Na formativa é que nós estamos acompanhando o processo do aluno [...]: primeiro, a gente ajuda, acompanha, avalia, dá feedback; segundo, retira um pouco todas estas ajudas para que ele aprenda a se autocriticar e também "consertar-se".

Embora a avaliação formativa não seja uma modalidade nova de avaliação, já prevista e explicada por Benjamim S. Bloom et al. (1971) desde os anos 70, ainda não é muito utilizada no ensino em geral, mesmo que muito veiculada, pois se trata de uma modalidade que requer do professor uma mudança profunda na sua postura pedagógica, e dos alunos uma mentalidade aberta para um novo sentido de aprendizagem escolar, com esforços e dedicação especiais, não estimulados pelo modo de vida em nossa sociedade.

Aliás, segundo Villas Boas (2002), a expressão “avaliação formativa" foi introduzida por Scriven, em 1967, como a designação de processos concebidos para permitirem ajustamentos sucessivos durante o desenvolvimento e a experimentação de um novo curriculum, manual ou método de ensino (p. 118).

Villas Boas ainda explicita:

com o cuidadoso acompanhamento dos professores, eles são convidados a participar da definição dos critérios de avaliação de seu trabalho e a aplicá-los. Isso thes possibilita compreender onde estão em termos de aprendizagem e o que deles é esperado [...]. Assim se constroem a confiança e a segurança. O envolvimento dos alunos no registro dos resultados thes dá a oportunidade de acompanhar seu desempenho por meio da avaliação contínua. (2002, p. 121-122)

A avaliação formativa, embora voltada para o aluno, pode constituir-se em excelente meio para o professor obter as informações necessárias para proceder aos ajustes ou à reorganização de seu processo pedagógico, quando verdadeiramente comprometido com a aprendizagem de seus alunos. Os indícios de uso da avaliação formativa pelos professores entrevistados podem ser considerados o que há de mais positivo a ser destacado em seus procedimentos avaliativos, por se confundir com o seu verdadeiro papel educativo. 
Com o mesmo espírito que orienta a avaliação formativa, o professor valoriza o diálogo com seus alunos, componente essencial para que ambos se entendam e trabalhem juntos, para que os últimos atinjam os objetivos esperados e se desenvolvam. Valemo-nos novamente de Hoffmann (1994, p. 148) ao abordar a importância do diálogo numa avaliação mediadora. Afirma a autora:

Entendo que a avaliação, enquanto relação dialógica, vai conceber o conhecimento como apropriação do saber pelo aluno e pelo professor, como ação-reflexão-ação que se passa na sala de aula em direção a um saber aprimorado, enriquecido, carregado de significados, de compreensão.

Com esse argumento, a autora nos leva a compreender que a avaliação possibilita ao professor estabelecer uma relação epistemológica com o aluno, por meio de uma reflexão aprofundada acerca das formas como se dá a sua compreensão sobre o objeto do conhecimento.

$O$ interessante é que o diálogo não ocorre apenas quando se conversa frente a frente. Os professores entrevistados elegeram suas próprias formas de estabelecer o diálogo com seus alunos, como nos contou H1: por exemplo, eu faço anotações e devolvo sob a forma de cartas. Se H1 observa que a classe baixou o ritmo, as expectativas, procura saber: $o$ que está acontecendo? Vocês estão mal-humorados por quê? Estão desinteressados por quê? Vamos conversar. Além disso, o professor explicita as regras do jogo para que o discente vá fazer o estágio. Assim, ele sabe de antemão o que é que está posto para aquele contrato didático.

Com o professor F4, as avaliações são decididas junto: eles escolhem. A gente sempre no início dos cursos vota como vai ser o curso. [...] Tudo é negociado, desde que eles mostrem desempenho, "mostrem serviço", digamos assim, mas é tudo negociado. Já o professor F5 considera positiva a preocupação de dar espaço para que a voz do aluno apareça. Ele explica: é uma co-responsabilidade, não sou eu que estou determinando a avaliação que vai ser feita, mas nós, enquanto grupo... o grupo decide não só os tipos, mas a ordem, inclusive.

Outra forma de dialogar é a de $\mathrm{C} 3$, que corrige o trabalho do aluno quantas vezes forem necessárias: corrijo, converso, devolvo novamente; isso eu vou fazendo constantemente. [...] atendo as equipes na minha sala, converso com eles, dou atendimento individual, porque é partindo dai que eu percebo que eles estão crescendo.

Também pelas conversas, M3 acaba detectando problemas de ordens diversas. E afirma: tenho critérios e digo: você precisa melhorar isso e aquilo, mas às vezes o problema é outro. Aí acaba surgindo uma espécie de cumplicidade e a coisa vai (M3). A1 está convencido de que é na busca do 
professor ser melhor a cada ano que a interação com o aluno acontece e é maior: porque o aluno sente que o professor também está buscando, e é uma busca séria! Então, o diálogo fica mais fácil, o crescimento, a interação pessoal é muito melhor.

Percebemos que são muitas alternativas valiosas visando ao aprendizado dos alunos: a negociação; as decisões conjuntas; o espaço democrático de interação, em que a voz do aluno pode aparecer; a consulta ao aluno para o uso de determinado procedimento, revelando o respeito à sua individualidade; o contrato pedagógico; as paradas necessárias para a conversa e o estabelecimento de rumos; as "cartas"; a interação; o espaço para o desabafo, que permite maior conhecimento dos alunos, entre outras.

De todas essas possibilidades, o que fica de princípio é a aproximação do professor com seus alunos, para trabalharem juntos, e por que não dizer aprenderem juntos, pois, como afirma Becker (1993, p. 147): não há educador tão sábio que nada possa aprender, nem educando tão ignorante que nada possa ensinar. Surge, dai, a concepção dialógica da educação problematizadora.

Cabe salientar que os procedimentos dos nossos professores, algumas vezes, ultrapassam as questões de ensino-aprendizagem escolar e atingem a esfera do diálogo como um encontro entre humanos, tão importante e cada vez mais raro, pelas condições que vão sendo impressas no trabalho do professor, nas instituições de ensino.

Associado diretamente ao diálogo, à comunicação do professor com seus alunos na avaliação, encontramos o feedback como outro aspecto recorrente nas respostas de nossos entrevistados.

Concordamos com Hadji (2001) de que o ato de avaliação, essencialmente no contexto escolar, sempre tem essa dimensão de comunicação. $\mathrm{O}$ avaliador se manifesta com relação ao modo como julga que suas expectativas foram satisfeitas e envia uma mensagem aos seus alunos. Somente assim a avaliação pronunciada pelo professor poderá, do ponto de vista da comunicação, tornar-se formativa (p. 109). Favoravelmente, inúmeras distorções podem ser eventualmente corrigidas por meio de uma reformulação e de um retorno da mensagem ao emissor para fins de confirmação ou de retificação, afirma o autor (p. 110). E isso ocorre pelo feedback.

Para otimizar sua ação, o professor, em sua atividade orientadora deve fazer uso adequado da informação reativa e articular feedback (pelo qual se situa em relação ao objetivo) e encaminhamento (por meio do qual ajusta a ação em relação ao objetivo). O necessário feedback aos alunos, acerca do seu desempenho nas atividades de aprendizagem, é, portanto, mais uma característica inerente à prática avaliativa formativa. 
Vários professores se manifestaram em relação ao feedback. Relembramos H1, que faz anotações e as devolve sob a forma de cartas. Nessas cartas, H1 observa a lógica das idéias e vai escrevendo o que está ou não interessante, ou o que está equivocado no texto. Também informa ao aluno se há contradições muito evidentes, explícitas no texto, que não são sustentáveis. Numa outra leitura, H1 faz sugestões, parágrafo a parágrafo: olha, tal autor fala sobre isso, leia. Vai fazendo indicações bibliográficas e uma avaliação panorâmica do texto. Na segunda avaliação, $\mathrm{H} 1$ pede a primeira e compara as duas, para dizer: olha até onde você avançou! o que você avançou, o que você precisa melhorar ainda.

Outro exemplo é de B2. Disse-nos: eu sempre valorizava muito o que o aluno me trazia e eu dava feedback por escrito, eu dava o retorno, perguntando coisas. E acrescentou: a importância destes retornos da prova é de aprendizado, é o aluno saber porque estou falando isso. É uma forma de fazer com que ele aprenda aonde eu quero chegar.

O professor L5 tem um sistema peculiar. Quando corrige a prova e dá a $1^{a}$ nota, diz aos alunos que eles têm 24 horas para refazê-la e, então, devolvê-la. Isso porque refazendo a prova, eles aprendem: todas as minhas provas têm minhas anotações, então eles já sabem onde eles erraram, onde está correto. Por sua vez, B5 nos relatou que sempre procurou descrever muito bem para os alunos o que esperava deles, para que não se sentissem perdidos. Depois, no tempo da supervisão, tinha um espaço para discussão e B5 procurava sempre reforçar tudo que eles tinham feito de positivo, de certo, de melhor no trabalho. $\mathrm{O}$ professor procurava não pensar pelos alunos, mas estimulá-los e reconhecer o esforço que fizeram para aprontar o material. Como resultado, B5 sentia que isso repercutia na relação, pois os alunos ficavam mais abertos também para sugestões.

Outro professor (C4) revelou-nos, em suas explicações, que para o aluno aprender, mesmo no ensino superior, e sobretudo no $1^{\circ}$ ano do ensino superior, o aluno precisa ter tarefas de curto prazo, com avaliação, mesmo que não valha nota. Com isso ele poderá avaliar, desafiar e ali ser corrigido no que errou e ser fortalecido no que acertou, de forma pública, de modo que todos possam aproveitar uns dos outros o que acertaram e o que erraram. E completou: até, se possível, durante o próprio trabalho do exercício, se a gente puder ver se ele está indo no caminho certo, acompanhar ali e já dar o feedback, se está indo bem e entendendo direito a questão ou se há algum equívoco.

Em cada relato dos professores, observamos o esforço e a dedicação para levar seus alunos ao aprendizado e ao desenvolvimento. A comunicação (não só a falada) se torna um estímulo para o aluno prosseguir e no caminho desejado. Quando o professor estabelece uma relação de confiança com o estudante e troca com ele mensagens pertinentes $e$ 
significativas sobre seus processos, os primeiros passos estão dados na direção de uma postura reflexiva, como nos alerta Hoffmann (2001, p.172). Já consciente da importância dessa postura um dos nossos entrevistados (C1) declarou: esta prática reflexiva e a questão do feedback são dois momentos de aprendizagem em que eu preciso investir.

$\mathrm{O}$ educador reflexivo prepara o aluno para uma aprendizagem reflexiva à medida que compartilha com ele sentimentos e descobertas, sugere e acata sugestões de novos encaminhamentos. Mais que apontar a direção aos alunos, Hoffmann (2001, p. 172) assiná-la: acompanha-os em seus percursos, vivendo a magia do inesperado.

Diretamente associado ao feedback, e nitidamente sob a influência da perspectiva da avaliação formativa, encontramos também relatos de professores que procuram dar diversas chances aos alunos para alcançar os objetivos ou como apoio àqueles que não apresentam de pronto o aprendizado. Nesse caminho, adaptam estratégias já conhecidas ou criam novas, como uma postura saudável, mesmo porque, às vezes, o problema de aprendizagem está menos na capacidade do aluno para aprender e mais nos modos de ensinar dos próprios professores.

O professor H1 declarou: aí fecho a correção, devolvo e se ele tiver tempo ou disposição ele me devolve novamente reescrito e aí fica nesse vai e vem. [...] Assim, tem o estágio, tem o relatório do estágio, e eu acabo dando várias chances. O Professor F1 também dá várias chances de reformulação e diz: $a$ reformulação é um elemento constante. O aluno não pode temer a reformulação.

Trabalhando no mesmo sentido, o professor F5 possibilita aos seus alunos escreverem o mesmo texto no mínimo três vezes para terem a chance de aprender com os seus próprios erros, com seus próprios acertos e com o seu próprio processo de reescrita. Afirmou F5: se a avaliação é vista como parte do processo de aprendizagem, ela realmente tem que contribuir para essa aprendizagem e não apenas testar essa aprendizagem. Também o Professor L5 tem essa prática: eles produzem um pequeno relatório, que eu levo para casa, leio, trago, discuto e eles refazem, voltam para mim, e aí eu avalio. Para completar os exemplos, podemos aprender com B5, que nos revelou: em todas as avaliações eu tinha o objetivo de estar falando: agora vocês sabem um pouco mais, então agora podem fazer um pouco melhor.

Verificamos que são muitas as formas de conduzir os alunos ao aprendizado. Aqueles que têm mais dificuldades deverão merecer mais atenção do professor. Muitas vezes, um procedimento simples - ter um feedback da atividade realizada e obter uma nova chance de refazê-la - pode causar um impacto muito positivo no aluno e estimulá-lo ao estudo, por ter merecido a confiança do professor. Como afirma Gimeno Sacristán (1998, p.329): o caráter formativo da avaliação está mais na intenção com a qual é realizada e no uso da informação que se obtém do que nas técnicas concretas. 
Nesse processo de ir e vir dos trabalhos entre alunos e professores, dentro do princípio da avaliação formativa, a nota, que precisa acontecer, para responder a uma exigência burocrática do sistema escolar, passa a ser uma conseqüência do aprendizado construído para muitos de nossos entrevistados, deixando, portanto, a posição de importância que ocupa em outras modalidades de avaliação. Exemplifiquemos com $\mathrm{C} 4$, quando afirmou que o aluno precisa ter tarefas de curto prazo, com avaliação, mesmo que não valha nota, só para avaliar, desafiar seu aprendizado. E com H2 que desenvolve muitas atividades nas quais existe um conceito de participação, que não é pela nota.

Entre os professores, também encontramos a manifestação daquele que se preocupa pouco com as notas, mas, contraditoriamente, atribui uma série delas, podendo causar ansiedade nos alunos enquanto não as divulga. Assim se expressou M1: E dessa somatória sai a nota final que é a coisa que menos me preocupa, e eu procuro passar isso pra eles [...] Eles brigam porque querem a nota mês a mês, mas a nota só vem no final.

A nota é algo artificial, uma exigência colocada de fora para dentro na escola (demanda do sistema social excludente), diferente da avaliação, que é algo natural à ação humana consciente, como nos explica Vasconcellos (2003, p. 115). Por isso, atribuir nota, embora o façamos tradicionalmente, não é a tarefa mais agradável do processo avaliativo.

\section{FINALIZANDO...}

Nossos entrevistados colaboraram imensamente conosco, pois nos forneceram um conjunto enorme de aspectos para a reflexão contínua acerca da avaliação de alunos no ensino superior. Podemos inferir que mesmo aqueles que utilizam estratégias pouco inovadoras ou construtivas, como, por exemplo, a de dar oito provas e trabalhos numa só disciplina, podem ter sido valorizados pelos alunos que os indicaram, não tanto pela estratégia em si, mas pelo compromisso percebido nesses professores, que buscam fazer o máximo que sabem e podem para exercer sua docência formadora, dentro das condições reais de trabalho no magistério.

Ao finalizar este texto, considerando a proposta de nossa investigação, de extrair lições das práticas positivas de avaliação dos professores indicados pelos alunos para o conjunto dos professores das licenciaturas e do ensino superior em geral, salientamos algumas observações que podem ser entendidas como tal, ligadas mais diretamente aos aspectos aqui analisados. Afirmamos pois, como positiva e recomendável: 
- a prática de uma avaliação que privilegia a orientação e o acompanhamento do aluno como parte de um processo de ensino. Esta orientação/acompanhamento está caracterizada como um atendimento ao aluno, de forma individual ou grupal, em outros espaços e tempos que não só o da sala de aula. A avaliação final é o ponto culminante de um processo, de sucessivas avaliações, mas também de toda uma interação baseada no diálogo e na interlocução professor/aluno visando ao crescimento e ao aprendizado deste último;

- a indissociabilidade entre a avaliação e a metodologia utilizada pelo professor. Os bons avaliadores apontados pelos alunos revelam-se também professores preocupados em organizar adequadamente todo o processo de ensino, e ao explicar sua avaliação inserem-na num contexto inerente à sua forma de trabalhar, ou seja, numa metodologia diferenciada;

- a prática de uma avaliação vinculada a um nível de exigência alto em relação aos alunos. Os bons avaliadores indicados pelos alunos não são aqueles que dão nota fácil, mas sim aqueles que possuem uma autoridade pedagógica para poder exigir e puxar os alunos para degraus mais elevados do conhecimento. A competência do professor na condução do processo autoriza moralmente sua exigência sobre o nível do trabalho do aluno (Freire, 1998).

Além disso, apreendemos um movimento de continuidade/ruptura presente nos processos de avaliação. Observamos que a maioria dos professores indicados como bons avaliadores foram aqueles que tiveram ousadia de romper com modelos tradicionais e avançar em direção a concepções e formas diferenciadas de avaliação, implícitas em novos paradigmas de ensino e educação.

Às lições aprendidas com a investigação, agregamos uma recomendação de Pozo (2002). O autor apresenta em seu livro dez mandamentos da aprendizagem, visando a inverter a lógica mais presente na realidade escolar, como uma espécie de orientação aos professores. Após explicá-los, acaba condensando-os em dois, aqui registrados, pelo seu teor provocativo para a reflexão de todo professor-educador-avaliador:

Professor: I - Refletirás sobre as dificuldades que teus aprendizes enfrentam e buscarás meios de ajudá-los a superá-las; II - Transferirás progressivamente para os alunos o controle de sua aprendizagem, sabendo que a meta de todo mestre é se tornar desnecessário. ( p.272-273)

Almejando uma avaliação positivamente fundamentada e baseada tanto em conhecimentos pedagógicos como no compromisso docente de trabalhar para o crescimento e o desenvolvimento dos alunos, pensamos que as políticas e estratégias de formação docente para o ensino superior, especialmente postas em prática em cursos de pós-graduação, necessitam 
dar a devida importância a esses conhecimentos e às conseqüentes discussões que envolvem os fins da educação, a competência profissional e o compromisso docente. Nesse sentido, é desejável também que um processo de auto-avaliação seja mais incentivado, tanto nas políticas de avaliação institucional quanto nas atividades individuais cotidianas dos docentes, como meio de reflexão permanente sobre as práticas de avaliação adotadas, para o que, esperamos, este trabalho possa contribuir.

\section{REFERÊNCIAS BIBLIOGRÁFICAS}

BECKER, Fernando. A Epistemologia do professor: o cotidiano da escola. Petrópolis: Vozes, 1993.

BERBEL, Neusi Aparecida Navas. A Pesquisa em didática e prática de ensino através da Metodologia da Problematização. XII ENCONTRO NACIONAL DE DIDÁTICA E PRÁTICA DE ENSINO. Curitiba: Champagnat, 2004, p. 231242.

(org.) Metodologia da Problematização. Experiências com questões de ensino superior. Londrina: Eduel, 1998.

. (org.) Semina. Londrina, v. 16, n. 2, out. 1995. (Serie Ciências Sociais e Humanas)

BERBEL, Neusi Aparecida Navas et al. Avaliação da aprendizagem no ensino superior: um retrato em cinco dimensões. Londrina: Eduel/Comped/Inep, 2001.

BLOOM, Benjamin S. et al. Handbook on formative and summative evaluation of student learning. New York: McGraw Hill, 1971.

BORDENAVE, Juan Díaz; PEREIRA, Adair Martins. Estratégias de ensino aprendizagem. Petrópolis: Vozes, 1982.

FREIRE, Paulo. Pedagogia da autonomia: saberes necessários à prática educativa. São Paulo: Paz e Terra, 1998.

GIMENO SACRISTÁN, Jose. Poderes instáveis em educação. Porto Alegre: Artes Médicas Sul, 1999.

A avaliação no ensino. In: ; PÉRES GOMES, A. I.

Compreender e transformar o ensino. 4. ed. Porto Alegre: Artmed, 1998. 
HADJI, Charles. Avaliação desmistificada. Porto Alegre: Artmed, 2001.

HOFFMANN, Jussara. Avaliar para promover. As setas do caminho. Porto Alegre: Mediação, 2001.

Avaliação mediadora: uma prática em construção da pré-escola à universidade. 3. ed. Porto Alegre: Educação \& Realidade, 1994.

KUENZER, Acácia Zeneida. A Relação entre teoria e prática na educação profissional. In: ROMANOWSKI, Joana Paulin; MARTINS, Pura Lúcia Oliver; JUNQUEIRA, Sergio R. A. (orgs.) XII ENDIPE. Conhecimento local e conhecimento universal: pesquisa, didática e ação docente. Curitiba: Champagnat, 2004.

LUCKESI, Cipriano Carlos. Avaliação da aprendizagem escolar. 3. ed. São Paulo: Cortez, 1996.

POZO, Juan Ignacio. Aprendizes e mestres. A nova cultura da aprendizagem. Porto Alegre: Artmed, 2002.

TURRA, Clódia Maria Godoy. Avaliação e reconstrução contínua da realidade. In: ENRICONE, Délcia; GRILLO, Marlene (orgs.) Avaliação. Uma discussão em aberto. 2. ed. rev. e amp. Porto Alegre: EDIPUCRS, 2003.

VASCONCELLOS, Celso dos Santos. Avaliação da aprendizagem: práticas de mudança por uma práxis transformadora. 6. ed. São Paulo: Libertad, 2003.

VASCONCELLOS, Maura Maria Morita. Avaliação e ética. Londrina: Eduel, 2001.

VÁZQUEZ, Adolfo Sánchez. Filosofia da Práxis. 4. ed. Rio de Janeiro: Paz e Terra, 1977.

VILLAS BOAS, Benigna Maria de Freitas. Construindo a avaliação formativa em uma escola de educação infantil e fundamental. In: (org.) Avaliação: políticas e práticas. Campinas: Papirus, 2002.

Recebido em: abril 2006

Aprovado para publicação em: setembro 2006 